\title{
GEOMETRY FOR SCHOOLS
}

By A. H. G. PALMER, M.A., and H. E. PARR, M.A.

Sixth Edition. 5s. Or in 2 parts, 3s. each.

"This book has been written to make the most use of the reduced time for geometry now available in many schools. The authors have cut down bookwork and substituted very many theoretical riders. ... They use stimulating devices for encouraging successful solution of riders. It is worth serious consideration."--JoURNAL OF EDUCATION.

"A great feature is made of easy riders, success in solving them will greatly encourage pupils. The bookwork is clearly set out, and is reduced to a minimum without neglect of essentials. And the examples are classified so that rapid selection can be made. An excellent course."-THE A.M.A.

\section{A SCHOOL MECHANICS BY C. V. DURELL, M.A.}

Twelfth Edition. In three parts, 3s. 6d. each. Parts I and II ave available together at $6 s$. $6 d$.

Part I deals mainly with one-dimensional problems. Parts I and II together cover the syllabus for the School Certificate. Part III contains the work required for the Higher School Certificate. "The bookwork and examples are admirable, and the whole book is very near the ideal introduction to mechanics."-JOURNAL OF EDUCATION.

\section{EXAMPLES IN MECHANICS}

By A. ROBSON, M.A., and C. J. A. TRIMBLE, M.A.

Second Edition. 4s. 6d. Hints, 5s. net.

"This book, intended for the use of those preparing for examinations of Higher Certificate or Scholarship standard should be extremely useful. . All those teaching Mechanics to Mathematical Specialists are warmly advised to get this book."-MatheMaTical GazetTE.

G. BELL \& SONS, LTD., PORTUGAL ST., W.C.2 


\section{A FIRST COURSE IN S T A T I S T I C S \\ BY D. CARADOG JONES, M.A.}

Eighth Edition. I7s. 6d. net. Part I separately, 8s. 6d. net. "An excellent 'first course' the examples are well chosen . . the work is clearly expressed."-MATHEMATICAL GAZETTE. "A very compact, clear and sufficiently complete account of the mathematical machinery employed in analysing raw statistical material and in deducing general statements regarding its characteristics."-JOURNAL OF EDUCATION.

\section{POLISHUP \\ YOUR MATHEMATICS}

By R. C. FAWDRY, M.A., B.Sc. Sixth Edition. 5s. net.

A general survey of the elementary parts of the subject which have a practical bearing in everyday life. Historical illustrations add to the interest of the book. "There is plenty of solid instruction as well as historical and practical illustration.

. The text is full of interesting and amusing information . this lively and instructive book would make a good prize for a boy or girl still at school."-MATHEMATICAL GAZETTE.



By M. WILLIAMS, M.A., B.Sc. Third Edition. 2s. 6 d. net.

"The most valuable contribution of this book to navigation training is its wealth of practical examples to be worked by the student (3० pp.) and the worked examples (I8 pp.) which are set out with extreme clarity and provide excellent models for the pupil. The subject is dealt with from an essentially practical standpoint, and the notes and hints give invaluable assistance to the pupil. . All navigation instructors should find this book useful. ... The general arrangement and type are of a high standard."-MATHEMATICAL GAZETTE.

G. BELL \& SONS, LTD., PORTUGAL ST., W.C.2 